\title{
Clinical use of magnetic resonance imaging in buttock augmentation with silicone implants: a retrospective analysis
}

\author{
Jiaqi Zhang, Chau Loon Wong, Jian Zhang, Zheng Su, Fen Shi, Chen Chen, Yongzhen Wang, \\ Xiaolian Xiao, Weiqiang Liang, Jinming Zhang \\ Department of Plastic Surgery, Sun Yat-sen Memorial Hospital, Sun Yat-sen University, Guangzhou, China \\ Contributions: (I) Conception and design: Jinming Zhang; (II) Administrative support: W Liang; (III) Provision of study materials or patients: Jiaqi \\ Zhang; (IV) Collection and assembly of data: CL Wong; (V) Data analysis and interpretation: Jian Zhang; (VI) Manuscript writing: All authors; (VII) \\ Final approval of manuscript: All authors. \\ Correspondence to: Jinming Zhang; Weiqiang Liang. Department of Plastic Surgery, Sun Yat-sen Memorial Hospital, Sun Yat-sen University, 107 \\ Yanjiang West Road, Guangzhou 510120, China. Email: zhjinm@mail.sysu.edu.cn; lweiq@mail.sysu.edu.cn
}

\begin{abstract}
Background: The objective of the current study was to retrospectively examine the morphological magnetic resonance imaging (MRI) characteristics of the gluteus maximus of buttock augmentation at levels of predetermined anatomic points.
\end{abstract}

Methods: The present study was a retrospective cross-sectional study. Adult women who underwent highquality MRI scanning at Sun Yat-sen Memorial Hospital of Sun Yat-sen University from January 2018 to January 2021 were included in this work. The transverse MRI data measured at the inferior point of the sacroiliac joint, just above the femoral head, and at the ischial tuberosity were collected and statistically analyzed.

Results: Fifty-two cases (104 sides of female gluteus maximus) were included in the final analysis. The A point (surgery starting point) were $54.4 \pm 6.34 \mathrm{~mm}, 54.91 \pm 5.57 \mathrm{~mm}$, and $73.91 \pm 5.57 \mathrm{~mm}$ away from the posterior midline at the level of inferior point of the sacroiliac joint, just above the femoral head, and at the ischial tuberosity, respectively. Accordingly, the thickness of the muscle at these locations was $16.0 \pm 4.17 \mathrm{~mm}$, $23.4 \pm 4.40 \mathrm{~mm}$, and $24.6 \pm 7.58 \mathrm{~mm}$, respectively. The diameter of the implant did not exceed $14.18 \pm 1.22 \mathrm{~cm}$. In addition, the gluteus maximus at the lowest point of the sacroiliac joint and above the femoral head exhibited an arc structure, which needs to be tilted to the deep plane during separation.

Conclusions: Dissimilar from previous experience of blind dissection, the gluteus maximus muscle can be more scientifically and reasonably dissected using the indexes for gluteus augmentation supplied in this study.

Keywords: Buttocks; prostheses and implants; silicone gels; magnetic resonance imaging (MRI); retrospective studies

Submitted Dec 29, 2021. Accepted for publication Feb 21, 2022.

doi: $10.21037 /$ atm-22-376

View this article at: https://dx.doi.org/10.21037/atm-22-376

\section{Introduction}

Buttock augmentation by enhancing the buttock volume and the lifting of the buttock has become one of the most common plastic surgical treatments in the modern era (1). There are generally five primary buttock augmentation techniques implemented: prosthetic gluteal augmentation, local tissue rearrangement, autologous fat grafting, local flaps, and hyaluronic acid gel injection (2,3). According to the United States cosmetic surgery statistics, prosthetic buttock augmentation has become one of the most commonly utilized techniques for buttock augmentation (4). Various implant approaches have been formed for prosthetic buttock augmentation, including subcutaneous placement, submuscular placement, intramuscular placement, and subfascial placement (5). Many physicians choose the 
intramuscular placement approach after comprehensively considering postoperative complications, postoperative effects, and patient satisfaction (5-8).

The gluteus maximus is the thickest muscle in the human body $(4-7 \mathrm{~cm})$. It starts from the iliac crest, sacrum, coccyx, and sacrotuberous ligaments, and ends at the thick line of the femur, the gluteal tuberosity, and the iliotibial band. The line from the middle and posterior third of the iliac crest to the greater trochanter is the lateral boundary of the gluteus maximus, and the line from the posterior superior iliac spine to the coccyx is the upper and lower boundary of the piriformis, respectively. The intersection of the horizontal line of the coccyx and the midline of the thigh is the sciatic nerve penetration location $(9,10)$. Vergara et al. introduced the intramuscular implantation technique of the gluteus maximus prosthesis by making a 6-7 $\mathrm{cm}$ intergluteal incision $4 \mathrm{~cm}$ above the anus and then cutting a 6-7 $\mathrm{cm}$ incision in the gluteus maximus fascia along the gluteus maximus fiber direction. After that, the buttock muscles are separated using the fingers by tilting $45^{\circ}$ to the deep surface from the lateral and upper boundaries to form the appropriate "implant pocket" (the gluteus maximus muscle implant space) $(11,12)$. The principles for inserting the prosthesis into the gluteus maximus were first proposed by Gonzalez et al., and are as follows: (I) dissection must be limited to the gluteus maximus; (II) the gluteus maximus must be cut in half to retain as much muscle as possible before and after the prosthesis $(13,14)$. In terms of the surgical approach incisions, González-Ulloa et al. introduced the bilateral the coccygeal region incision, infra-gluteal sulcus incision, and prolongation of the medial gluteal sulcus incision $(15,16)$. Nevertheless, no matter what kind of surgical approach incision is chosen, augmentation surgery is basically carried out under blind vision.

To better separate the gluteus maximus evenly in blindsight during the augmentation operation, it is necessary to understand the anatomical structure of the gluteus maximus before surgery. Based on different surgical approach incisions, the soft tissue thickness, gluteus maximus width and thickness, and some accurate parameters (anatomic angles) are needed to define the muscular incision site and appropriate intramuscular separation direction. The fillers in soft tissue for buttock augmentation include autologous fat, hyaluronic acid, and silicone implants, all of which have different signal intensities in magnetic resonance imaging (MRI). In addition, MRI, computed tomography (CT), and ultrasound have been used to identify the expected appearance and complications after buttock augmentation (17).

However, according to our literature search, no study has used MRI parameters to supply accurate anatomic evaluation for patients in buttock augmentation. The objective of the present study was to observe and study the morphological MRI characteristics of patients who have undergone the gluteus maximus of buttock augmentation with silicone implants at levels of predetermined anatomic points.

We present the following article in accordance with the STROBE reporting checklist (available at https://atm. amegroups.com/article/view/10.21037/atm-22-376/rc).

\section{Methods}

\section{Ethical approval}

All procedures performed in this study involving human participants were in accordance with the Declaration of Helsinki (as revised in 2013). The protocol of the study was approved by the Research Ethics Board of Sun Yat-sen Memorial Hospital, Sun Yat-sen University (No. SYSECKY-KS-2021-298). Informed consent was waived due to the retrospective and anonymous characteristics of the study.

\section{Participants}

Adult women, who once underwent pelvic MRI scanning at Sun Yat-sen Memorial Hospital of Sun Yat-sen University from January 2018 to January 2021, were screened. The inclusion criteria were as follows: (I) age between 18 to 50 years old, and (II) high-quality MRI scanning results sufficient for analysis. The exclusion criteria were as follows: (I) hip muscle damage due to fractures or trauma, (II) femoral head necrosis, (III) problem of malignant tumor pelvic metastasis or gluteus maximus metastasis, (IV) hip muscle local lesions or atrophy, (V) problems associated with being bedridden for extended time periods, unable to walk independently, or (VI) lack of important information needed for the present study.

\section{MRI scanning and measurements}

We performed MRI examinations of the pelvis using a 3.0T system (MAGNETOM Skyra, Siemens Healthcare, Erlangen, Germany). The MRI sequences included coronal T1-weighted imaging (T1WI) and transverse T2WI. We used the coronal T1WI images to define 3 scanning levels, including the lowest point of the sacroiliac joint 

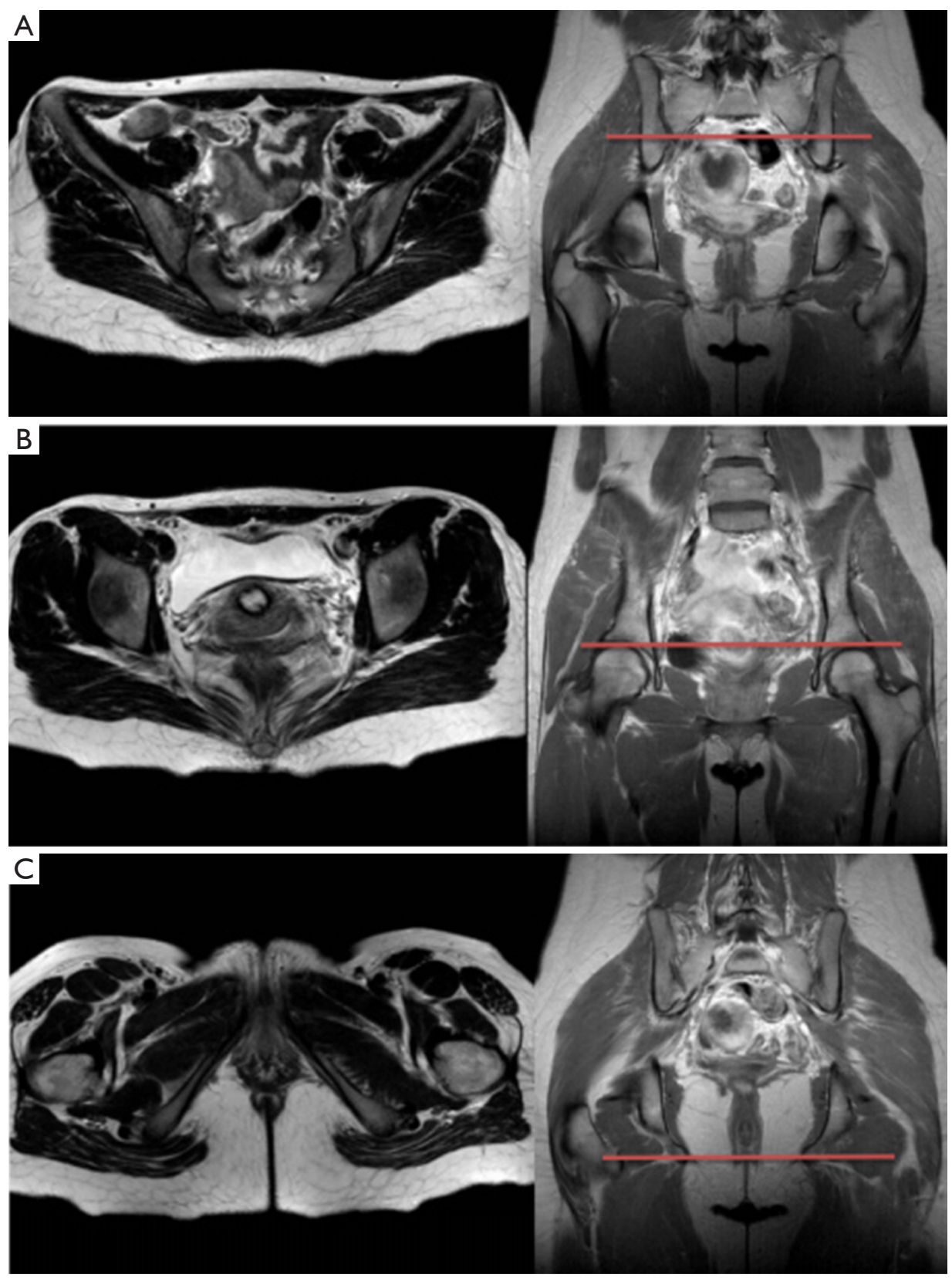

Figure 1 The coronal T1WI (left) and transverse T2WI (right) MRI images of the pelvis. (A) The lowest point of the sacroiliac joint, (B) above the femoral head, and at (C) the ischial tuberosity. MRI, magnetic resonance imaging; T1WI, T1-weighted imaging; T2WI, T2weighted imaging.

(SIJ), the point just above the femoral head, and the ischial tuberosity. Then, transverse T2WI images at the 3 levels were used to measure the index of left- and right-side glutes (Figure 1). The detailed imaging parameters are listed in Table 1. We delineated the gluteus maximus muscle using post-processing software on a GE MRI workstation (GE,
Advantage Windows 4.5 workstation; GE Healthcare, Chicago, IL, USA) to calculate the cross-sectional area of the gluteus maximus muscle.

In the transverse T2WI images, the starting point of the medial tendon of one side of the gluteus maximus was defined as $\mathrm{O}$, and the midpoint of the lateral gluteus 
Table 1 Pelvic MRI sequence parameters

\begin{tabular}{lcc}
\hline Sequence parameters & Coronal T1WI & Transverse T2WI \\
\hline TR/TE $(\mathrm{ms})$ & $629 / 9.8$ & $3104 / 110$ \\
FoV $(\mathrm{mm})$ & $320 \times 320$ & $350 \times 350$ \\
Matrix & $320 \times 320$ & $288 \times 384$ \\
Slice thickness $(\mathrm{mm})$ & 4 & 4 \\
Gap $(\mathrm{mm})$ & 0.8 & 0.8 \\
Fat suppression (yes/no) & No & No \\
Flip angle $\left({ }^{\circ}\right)$ & 130 & 130 \\
Acquisition time & 1 minute 46 seconds & 1 minute 41 seconds \\
\hline
\end{tabular}

MRI, magnetic resonance imaging; TR, repetition time; TE, echo time; FoV, field of view; T1WI, T1-weighted imaging; T2WI, T2-weighted imaging.
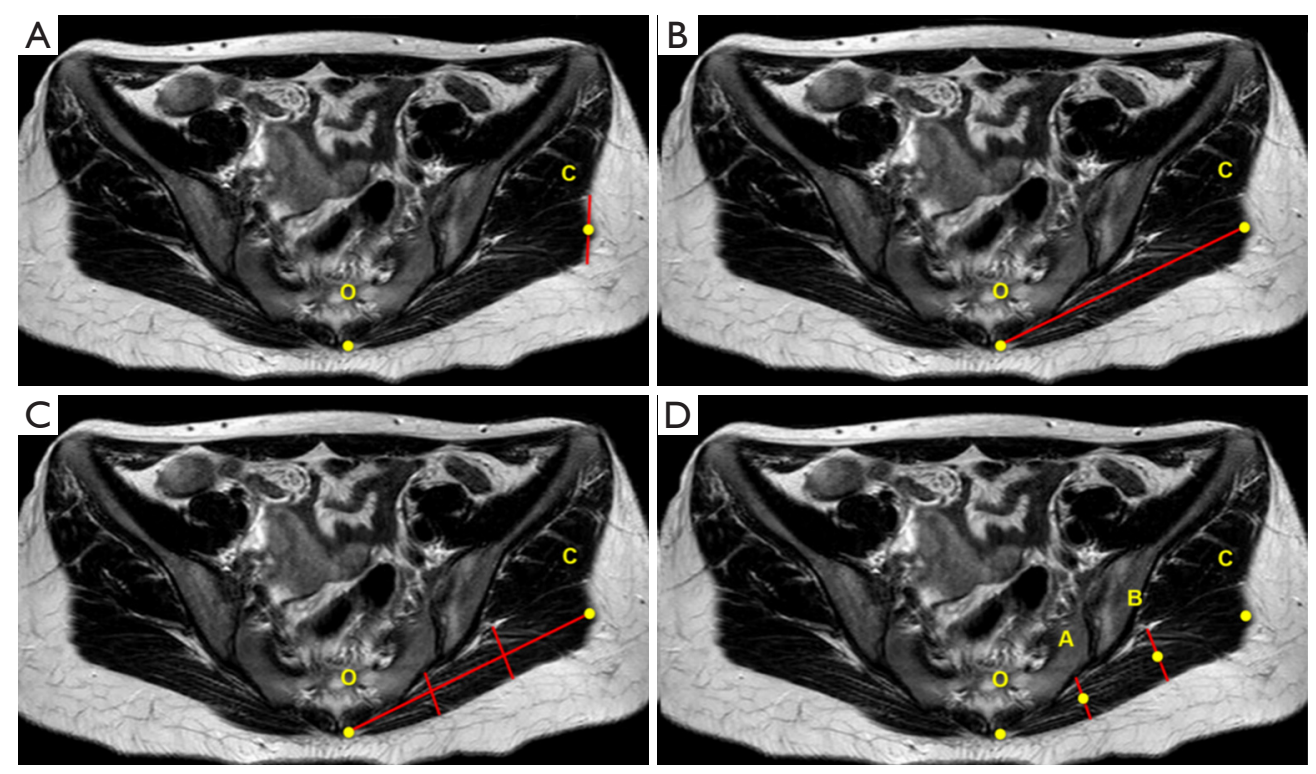

Figure 2 Schematic diagram by transverse T2WI images of measurement indicators. (A) The starting point of the medial tendon of one side of the gluteus maximus was defined as $\mathrm{O}$ and the midpoint of the lateral gluteus maximus was defined as $\mathrm{C}$. The (B) OC line is drawn and the (C) vertical lines to $\mathrm{OC}$ at $1 / 3 \mathrm{OC}$ and $2 / 3 \mathrm{OC}$ were made in the gluteus maximus muscle. (D) The midpoints of the vertical lines were defined as point $\mathrm{A}$ and point $\mathrm{B}$, respectively, and the length of the vertical lines were denoted as the thickness of gluteus maximus muscle at points A and B, respectively. T2WI, T2-weighted imaging.

maximus was defined as $\mathrm{C}$ (Figure $2 A$ ). Using these 2 points, an OC line was drawn (Figure $2 B$ ), which was considered the width of the gluteus maximus. Then, vertical lines to the $\mathrm{OC}$ line at $1 / 3 \mathrm{OC}$ and $2 / 3 \mathrm{OC}$ were made within the gluteus maximus muscle (Figure 2C). Finally, the midpoint of the vertical line at $1 / 3 \mathrm{OC}$ and $2 / 3 \mathrm{OC}$ were defined as point $\mathrm{A}$ and point $\mathrm{B}$, respectively. Therefore, the length of the vertical line was the thickness of the gluteus maximus muscle at point $\mathrm{A}$ and point $\mathrm{B}$ (Figure $2 \mathrm{D}$ ). The body surface projections of $\mathrm{O}, \mathrm{A}, \mathrm{B}$, and $\mathrm{C}$ were marked as $\mathrm{O}^{\prime}, \mathrm{A}^{\prime}$, $\mathrm{B}^{\prime}$, and $\mathrm{C}^{\prime}$, respectively.

We set line $\mathrm{L}$ as the posterior midline in the transverse T2WI images. The angle of LOA $(\angle \mathrm{LOA})$ was the inclusive angle of line $\mathrm{L}$ and line OA. This angle was that from point $\mathrm{O}$ to point A during the vertical surgical approach (Figure $3 A$ ). The supplementary angle of 

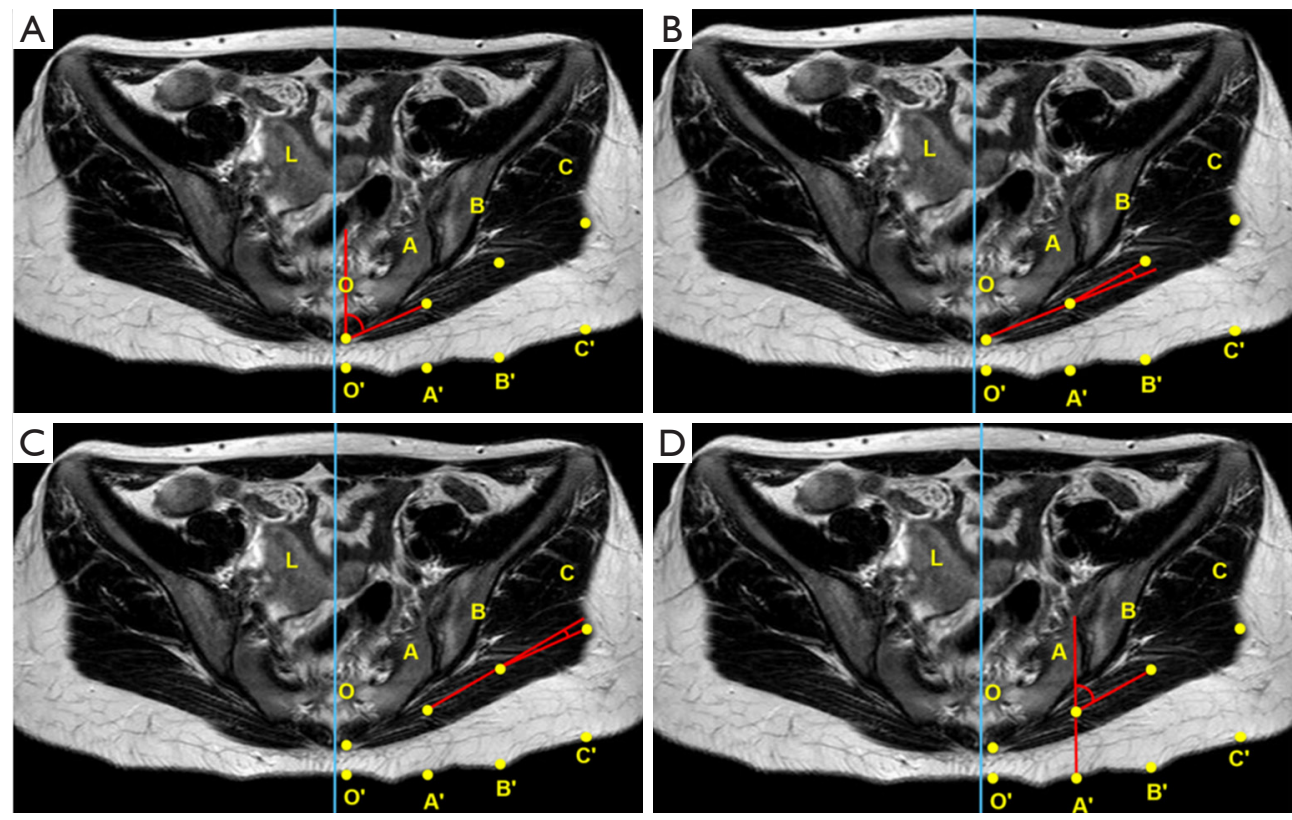

Figure 3 Schematic diagram by transverse T2WI images of measurement indicators. (A) $\angle \mathrm{LOA}$ is the angle between the posterior midline $\mathrm{L}$ and line $\mathrm{OA} ;(\mathrm{B})$ the supplementary $\angle \mathrm{OAB}$ is the angle between the extension line of $\mathrm{OA}$ and line $\mathrm{AB}$; $(\mathrm{C})$ the supplementary $\angle \mathrm{ABC}$ is the angle between the extension line of $\mathrm{AB}$ and line $\mathrm{BC}$; (D) the supplementary $\angle \mathrm{A} ' \mathrm{AB}$ is the angle between the extension line of $\mathrm{A}$ 'A and line AB. T2WI, T2-weighted imaging.

$\mathrm{OAB}$ (supplementary $\angle \mathrm{OAB}$ ) was the angle between the extension line $\mathrm{OA}$ and line $\mathrm{AB}$, at which the operation approach should turn from $\mathrm{OA}$ to point $\mathrm{B}$. When the angle was opened towards the deep gluteus maximus muscle, it was marked as a positive angle. Conversely, when the angle was opened towards the superficial layer, it was marked as a negative angle. The supplementary $\angle \mathrm{OAB}$ was used to differentiate the intraoperative angle between the deep layer and the superficial layer (Figure 3B). The supplementary angle of $A B C$ (supplementary $\angle A B C$ ) was the included angle between the extension line $\mathrm{AB}$ and line $\mathrm{BC}$, and was the angle at which the operation approach should turn from $\mathrm{AB}$ to point $\mathrm{C}$. When the angle was opened towards the deep gluteus maximus muscle, it was marked as a positive angle and when the angle was opened towards the superficial layer, it was marked as a negative angle. The supplementary $\angle \mathrm{ABC}$ was used to distinguish the angle towards the deep layer or the superficial layer during the operation (Figure $3 C$ ). The supplementary angle of $\mathrm{A}^{\prime} \mathrm{AB}$ $\left(\angle \mathrm{A}^{\prime} \mathrm{AB}\right)$ was the included angle between the extension line $\mathrm{A}^{\prime} \mathrm{A}$ and line $\mathrm{AB}$. The supplementary $\angle \mathrm{A}^{\prime} \mathrm{AB}$ was the angle turn from $\mathrm{A}^{\prime} \mathrm{A}$ to $\mathrm{B}$ during the vertical approach when $\mathrm{A}^{\prime}$ point was the incision site (Figure 3D).
The lengths from point $\mathrm{O}, \mathrm{A}, \mathrm{B}$, and $\mathrm{C}$ to their body surface projections $\mathrm{O}^{\prime}, \mathrm{A}^{\prime} \mathrm{B}^{\prime}$, and $\mathrm{C}^{\prime}$ (denoted as $\mathrm{OO}^{\prime}, \mathrm{AA}^{\prime}$, $\mathrm{BB}^{\prime}$, and $\mathrm{CC}^{\prime}$ ) were the thickness of soft tissue at point $\mathrm{O}, \mathrm{A}, \mathrm{B}$, and $\mathrm{C}$ (including gluteus maximus, fat, and skin), respectively. The vertical distance from $\mathrm{O}^{\prime}, \mathrm{A}^{\prime}, \mathrm{B}^{\prime}$, and $\mathrm{C}^{\prime}$ to the posterior midline $\mathrm{L}$ was recorded as the vertical distance from $\mathrm{O}, \mathrm{A}, \mathrm{B}$, and $\mathrm{C}$ to the posterior midline, respectively (Figure 4). The cross-sectional area of the gluteus maximus was recorded using the transverse $\mathrm{T} 2 \mathrm{WI}$ images at the corresponding position (Figure 5).

\section{Outcomes and data collection}

The primary outcomes included the width of the gluteus maximus (measured by the length of OC), and the gluteus maximus thickness at points $\mathrm{A}$ and $\mathrm{B}$. The angles of $\angle \mathrm{LOA}$, the supplementary $\angle \mathrm{ABC}$, and the supplementary $\angle \mathrm{A}^{\prime} \mathrm{AB}$ were also collected.

Secondary outcomes included the supplementary $\angle \mathrm{OAB}$, the soft tissue thickness at each point (i.e., O, A, B, and C), the distance from each point (i.e., $\mathrm{O}^{\prime}, \mathrm{A}^{\prime}, \mathrm{B}^{\prime}$, and $\mathrm{C}^{\prime}$ ) to the posterior midline, and the cross-sectional area (CSA) of the gluteus maximus at each level (i.e., the inferior point of 


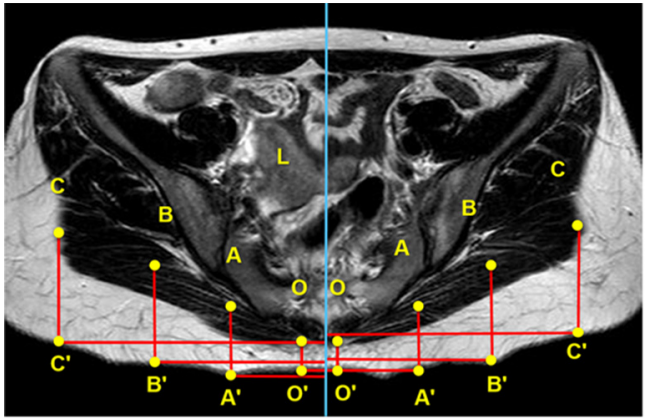

Figure 4 Schematic diagram by transverse T2WI images of measurement indicators. The length of $\mathrm{OO}^{\prime}, \mathrm{AA}^{\prime}, \mathrm{BB}^{\prime}$, and $\mathrm{CC}^{\prime}$ indicates the thickness of soft tissue at point $\mathrm{O}, \mathrm{A}, \mathrm{B}$, and $\mathrm{C}$ (including gluteus maximus, fat, and skin), respectively. The vertical distance from $\mathrm{O}^{\prime}, \mathrm{A}^{\prime}, \mathrm{B}^{\prime}$ and $\mathrm{C}^{\prime}$ to the posterior midline was recorded as the distance from $\mathrm{O}, \mathrm{A}, \mathrm{B}$ and $\mathrm{C}$ to the posterior midline, respectively. T2WI, T2-weighted imaging.

the sacroiliac joint, just above the femoral head, and ischial tuberosity). The baseline data collection included patients' age, height, and body mass index (BMI).

\section{Statistical analysis}

The discontinuous data (e.g., age) are represented as median and interquartile range (IQR), and continuous data (e.g., height, weight, and BMI) are represented as mean \pm standard deviation (SD). By default, the population sample was normally distributed, and the differences of each measurement index between the left and right sides of the gluteus maximus were compared with a paired sample $t$-test. A 2-sided $\mathrm{P}<0.05$ was considered statistically significant. In this study, the SPSS 24.0 software (IBM Corp., Armonk, NY, USA) was used for statistical analysis.

\section{Results}

\section{Patients and characteristics}

A total of 192 women had pelvic MRI scanning records at Sun Yat-sen Memorial Hospital of Sun Yat-sen University between January 2018 and January 2021. According to our eligibility criteria, 52 cases (104 sides of female gluteus maximus) were included in the final analysis (Figure 6). The age of the included cases ranged from 19 to 50 years old (median: 38.5 years old, IQR 30-43.25 years old). The mean height, weight, and BMI were $1.59 \pm 0.05 \mathrm{~m}, 55.52 \pm 7.76 \mathrm{~kg}$, and $22 \pm 3.26 \mathrm{~kg} / \mathrm{m}^{2}$, respectively.

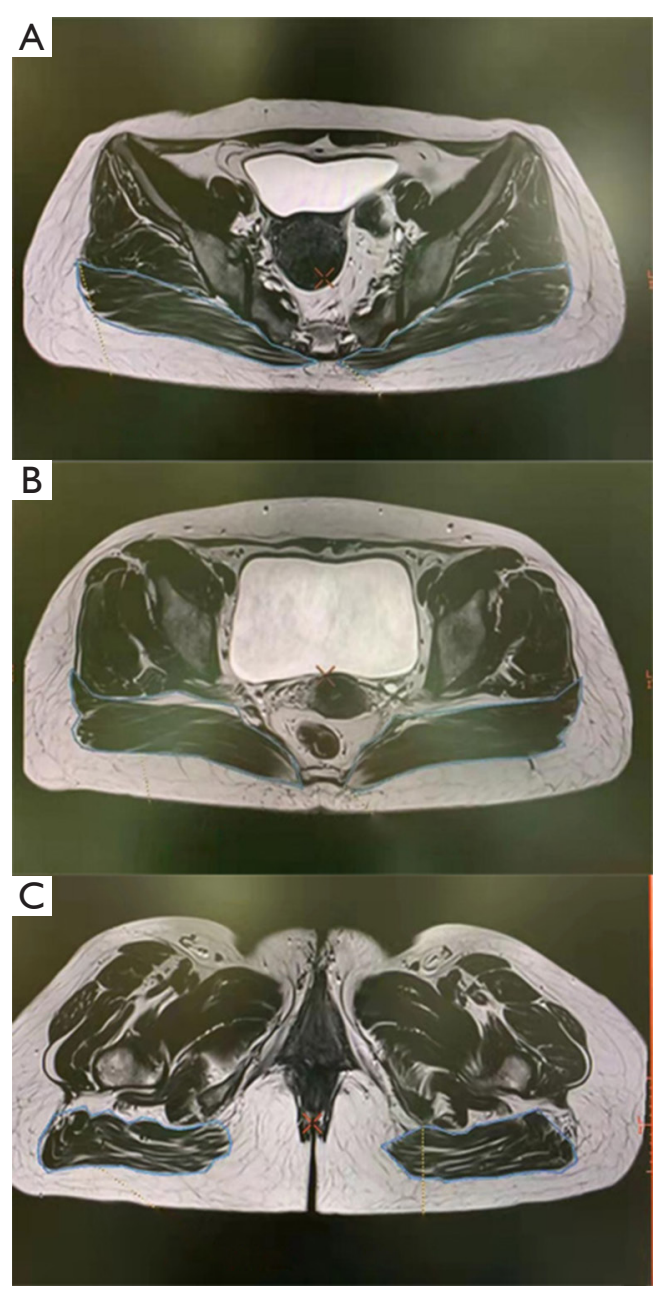

Figure 5 Schematic diagram by transverse T2WI images of measurement indicators. The cross-sectional areas of the gluteus maximus at the lowest point of the sacroiliac joint (A), the upper part of the femoral head (B) and at the ischial tuberosity (C), respectively. T2WI, T2-weighted imaging.

\section{The level of the inferior point of the SIF}

The average length of OC at the lowest point of the SIJ level was $125.32 \pm 13.20 \mathrm{~mm}$ for the 104 samples. No statistical difference was found in the comparison of the left and right sides $(\mathrm{P}=0.28)$. At the same time, the average gluteus maximus thickness at points $\mathrm{A}$ and $\mathrm{B}$ were $16.03 \pm 4.17$ and $24.66 \pm 4.84 \mathrm{~mm}$, respectively. Similarly, there was no statistical difference in the thickness between the left and right sides at points $\mathrm{A}(\mathrm{P}=0.12)$ and $\mathrm{B}(\mathrm{P}=0.30)$ (Table 2). The average $\angle \mathrm{LOA}$, the supplementary $\angle \mathrm{OAB}$, the supplementary $\angle \mathrm{ABC}$, and the supplementary $\angle \mathrm{A}^{\prime} \mathrm{AB}$ were $69.77 \pm 5.35^{\circ}, 6.54 \pm 5.43^{\circ},-2.73 \pm 6.09^{\circ}$, and $116.57 \pm 4.62^{\circ}$, 

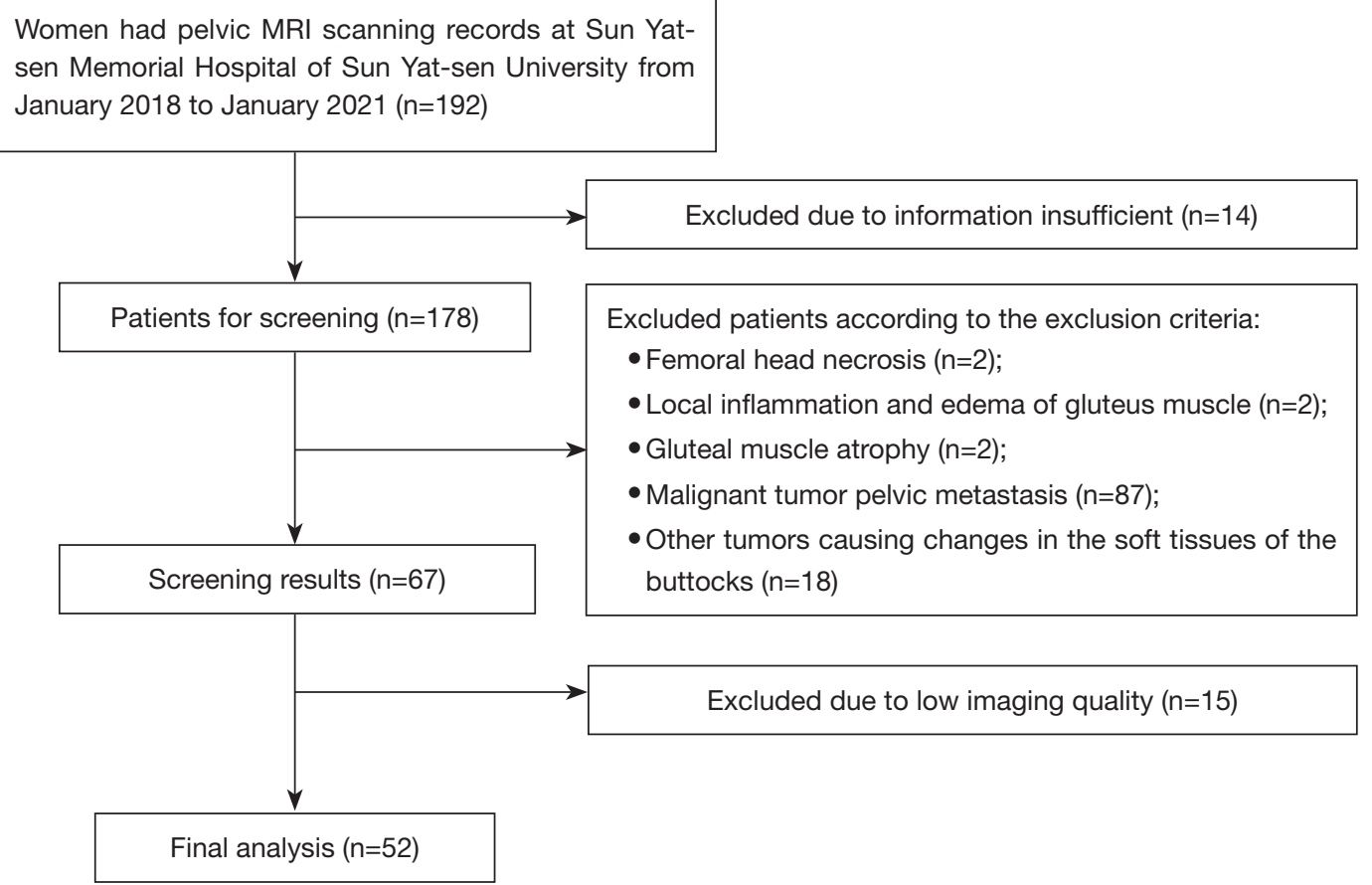

Figure 6 The workflow diagram of the present study.

respectively. There was no statistical difference in the angle between the left and right sides for the average $\angle \mathrm{LOA}(\mathrm{P}=0.47)$, the supplementary $\angle \mathrm{OAB}(\mathrm{P}=0.27)$, the supplementary $\angle \mathrm{ABC}(\mathrm{P}=0.32)$, and the supplementary $\angle \mathrm{A}^{\prime} \mathrm{AB}(\mathrm{P}=0.87)$ (Table 2).

The average soft tissue thickness at each point (i.e., $\mathrm{O}, \mathrm{A}, \mathrm{B}$, and $\mathrm{C}$ ), denoted as $\mathrm{OO}^{\prime}, \mathrm{AA}^{\prime}, \mathrm{BB}^{\prime}$, and $\mathrm{CC}^{\prime}$, was $15.78 \pm 6.52$, $28.14 \pm 6.31,41.59 \pm 6.68 \mathrm{~mm}$, and $49.21 \pm 8.85 \mathrm{~mm}$ for the 104 samples, respectively. There was no statistical difference between the left and right sides for the average length of $\mathrm{OO}^{\prime}(\mathrm{P}=0.23), \mathrm{AA}^{\prime}(\mathrm{P}=0.06), \mathrm{BB}^{\prime}(\mathrm{P}=0.13)$, or $\mathrm{CC}^{\prime}(\mathrm{P}=0.52)$ (Table 2).

The average vertical distance between each body projection point (i.e., $\mathrm{O}^{\prime}, \mathrm{A}^{\prime}, \mathrm{B}^{\prime}$, and $\mathrm{C}^{\prime}$ ) and the posterior midline was $14.50 \pm 7.32,54.40 \pm 6.34,91.51 \pm 8.34 \mathrm{~mm}$, and $130.11 \pm 11.62 \mathrm{~mm}$, respectively, for the 104 samples. The average vertical distance from $\mathrm{B}^{\prime}(\mathrm{P}=0.04)$ and $\mathrm{C}^{\prime}(\mathrm{P} \leq 0.05)$ to the posterior midline was statistically longer on the left side than on the right side; however, no statistical difference for this distance was found between the left and right sides for $\mathrm{O}^{\prime}(\mathrm{P}=0.64)$ and $\mathrm{A}^{\prime}(\mathrm{P}=0.13)$. The average cross-sectional area of the gluteus maximus at this level was $2,486.43 \pm 623.08 \mathrm{~mm}^{2}$ for all 104 samples. There was no statistical difference in average cross-sectional area of the gluteus maximus between the left and right sides $(\mathrm{P}=0.72)$ (Table 2).

\section{The level just above the femoral head}

The average length of $\mathrm{OC}$ at the level just above the femoral head was $141.76 \pm 12.15 \mathrm{~mm}$ for the 104 samples. No statistical difference was found in the comparison of the left and right sides $(\mathrm{P}=0.84)$. At the same time, the average gluteus maximus thickness at points $\mathrm{A}$ and $\mathrm{B}$ were $23.41 \pm 4.40$ and $30.64 \pm 4.57 \mathrm{~mm}$, respectively. Similarly, there was no statistical difference in the thickness between the left and right sides at points $\mathrm{A}(\mathrm{P}=0.58)$ and $\mathrm{B}(\mathrm{P}=0.09)$ (Table 2).

The average $\angle \mathrm{LOA}$, the supplementary $\angle \mathrm{ABC}$, the supplementary $\angle \mathrm{A}^{\prime} \mathrm{AB}$, and the supplementary $\angle \mathrm{OAB}$ were $62.36 \pm 5.65^{\circ}, 0.74 \pm 8.10^{\circ}, 109.74 \pm 5.52^{\circ}$, and $-7.43 \pm 6.82^{\circ}$, respectively. There was no statistical difference in the angle between the left and right sides for the average $\angle \mathrm{LOA}(\mathrm{P}=0.60)$, the supplementary $\angle \mathrm{ABC}(\mathrm{P}=0.14)$, the supplementary $\angle \mathrm{A}^{\prime} \mathrm{AB}(\mathrm{P}=0.27)$, or the supplementary $\angle \mathrm{OAB}(\mathrm{P}=0.97)$ (Table 2).

The average soft tissue thickness at each point (i.e., $\mathrm{O}$, $\mathrm{A}, \mathrm{B}$, and $\mathrm{C}$ ), denoted as $\mathrm{OO}^{\prime}, \mathrm{AA}^{\prime}, \mathrm{BB}^{\prime}$, and $\mathrm{CC}^{\prime}$, were $14.83 \pm 6.17,34.07 \pm 5.59,43.55 \pm 6.01$, and $50.61 \pm 10.00 \mathrm{~mm}$ for the 104 samples, respectively. There was no statistical difference between the left and right sides for the average length of $\mathrm{OO}^{\prime}(\mathrm{P}=0.65)$, $\mathrm{AA}^{\prime}(\mathrm{P}=0.16)$, $\mathrm{BB}^{\prime}(\mathrm{P}=0.58)$, and 


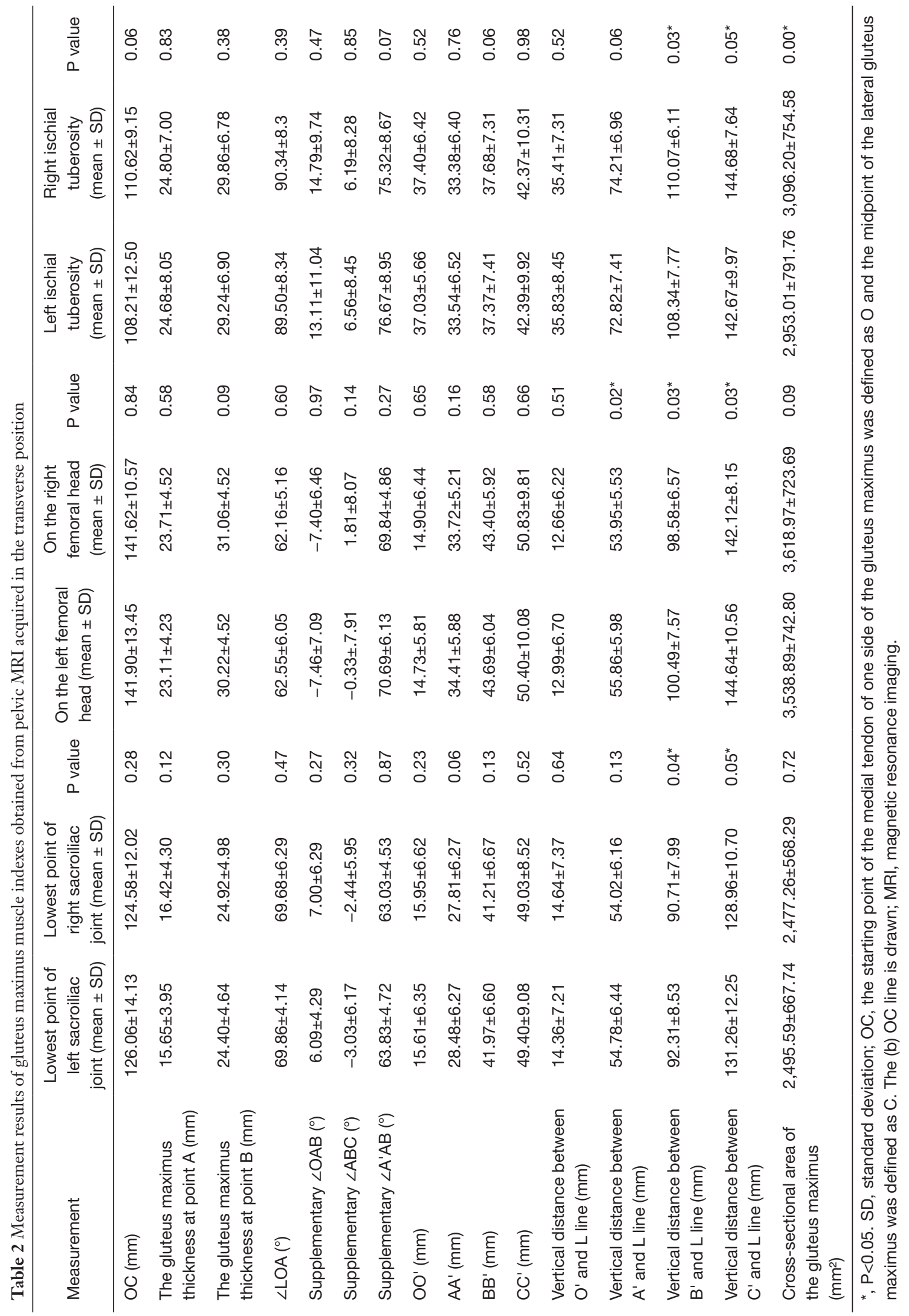


$\mathrm{CC}^{\prime}(\mathrm{P}=0.66)$ (Table 2).

The average vertical distance between each body projection point (i.e., $\mathrm{O}^{\prime}, \mathrm{A}^{\prime}, \mathrm{B}^{\prime}$, and $\mathrm{C}^{\prime}$ ) and the posterior midline were $12.82 \pm 6.50,54.91 \pm 5.87,99.54 \pm 7.19$, and $143.38 \pm 9.56 \mathrm{~mm}$ for the 104 samples, respectively. The average vertical distance from the point $\mathrm{O}^{\prime}$ to the posterior midline displayed no statistical difference between the left side and right side $(\mathrm{P}=0.51)$; however, a statistical difference was found between the left and right sides for all the other body projection points (i.e., $\mathrm{A}^{\prime}, \mathrm{P}=0.02 ; \mathrm{B}^{\prime}, \mathrm{P}=0.03$; and $\mathrm{C}^{\prime}$, $\mathrm{P}=0.03)$. The average cross-sectional area of the gluteus maximus at this level was $3,578.93 \pm 737.95 \mathrm{~mm}^{2}$ for all 104 samples. There was no statistical difference in average cross-sectional area of the gluteus maximus between the left and right sides $(\mathrm{P}=0.09)$ (Table 2).

\section{The level of the ischial tuberosity}

The average length of OC at the ischial tuberosity level was $109.41 \pm 11.07 \mathrm{~mm}$ for the 104 samples. No statistical difference was found in the comparison of the left and right sides $(\mathrm{P}=0.06)$. At the same time, the average gluteus maximus thickness at points $A$ and $B$ were $24.74 \pm 7.58$ and $29.55 \pm 6.88 \mathrm{~mm}$, respectively. Similarly, there was no statistical difference in the thickness between the left and right sides at points $\mathrm{A}(\mathrm{P}=0.83)$ or point $\mathrm{B}(\mathrm{P}=0.38)$ (Table 2$)$.

The average $\angle \mathrm{LOA}$, the supplementary $\angle \mathrm{ABC}$, the supplementary $\angle \mathrm{A}^{\prime} \mathrm{AB}$, and the supplementary $\angle \mathrm{OAB}$ for 104 samples were $89.92 \pm 8.29^{\circ}, 6.37 \pm 8.41^{\circ}, 104.01 \pm 8.79^{\circ}$, and $13.95 \pm 10.50^{\circ}$, respectively. There was no statistical difference in the angle between the left and right sides for the average $\angle \mathrm{LOA}(\mathrm{P}=0.39)$, the supplementary $\angle \mathrm{ABC}$ $(\mathrm{P}=0.85)$, the supplementary $\angle \mathrm{A}^{\prime} \mathrm{AB}(\mathrm{P}=0.07)$, and the supplementary $\angle \mathrm{OAB}(\mathrm{P}=0.47)$ (Table 2).

The average soft tissue thickness at each point (i.e., O, $\mathrm{A}, \mathrm{B}$, and $\mathrm{C}$ ), denoted as $\mathrm{OO}^{\prime}, \mathrm{AA}^{\prime}, \mathrm{BB}^{\prime}$, and $\mathrm{CC}^{\prime}$, were $37.21 \pm 6.08,33.46 \pm 6.49,37.52 \pm 7.43$, and $42.38 \pm 10.17 \mathrm{~mm}$ for the 104 samples, respectively. There was no statistical difference between the left and right sides for the average length of $\mathrm{OO}^{\prime}(\mathrm{P}=0.52), \mathrm{AA}^{\prime}(\mathrm{P}=0.76), \mathrm{BB}^{\prime}(\mathrm{P}=0.06)$, or $\mathrm{CC}^{\prime}$ $(\mathrm{P}=0.98)$ (Table 2).

For the 114 samples, the average vertical distance between each body projection point (i.e., $\mathrm{O}^{\prime}, \mathrm{A}^{\prime}, \mathrm{B}^{\prime}$, and $\left.\mathrm{C}^{\prime}\right)$ and the posterior midline was $35.62 \pm 7.94,73.52 \pm 7.26$, $109.20 \pm 7.08$, and $143.68 \pm 8.98 \mathrm{~mm}$, respectively. The average vertical distance from $\mathrm{B}^{\prime}(\mathrm{P}=0.03)$ and $\mathrm{C}^{\prime}(P<0.05)$ to the posterior midline was statistically longer on the left side than the right side, however, no statistical difference of this distance was found between the left and right sides for $\mathrm{O}^{\prime}(\mathrm{P}=0.52)$ and $\mathrm{A}^{\prime}(\mathrm{P}=0.06)$. The average crosssectional area of the gluteus maximus at this level was $3,024.60 \pm 780.46 \mathrm{~mm}^{2}$ for all 104 samples. There was a significant difference in average cross-sectional area of the gluteus maximus between the left and right sides $(P<0.001)$ at this level (Table 2).

\section{Discussion}

MRI is the gold standard for evaluating muscle volume and three-dimensional shape. It is also the reference index for other methods in terms of evaluating muscle volume $(18,19)$. Evenly stripping the glutes is critical to the success of a prosthetic buttock augmentation, by which the thickness of the anterior and the posterior implant pocket wall is consistent. Uneven or too shallow stripping of gluteus maximus thickness may result in postoperative asymmetry or reoperation due to implant complications that include implant shift or leakage (8). The present study supplies crucial indexes at the levels of the inferior SIJ, just above the femoral head, and of the ischial tuberosity, including the width of the gluteus maximus, the gluteus maximus thickness, and some essential angles that are necessary knowledge for surgery. We chose these 3 levels to study because at these levels it is easy to standardize the glutes measurement due to noticeable osseous marks in pelvic MRI. We then chose the level of ischial tubercle because it is the anatomical lower boundary selected by most clinicians and patients for gluteus maximus augmentation with implants (20-22). Finally, Homma et al. found that the maximum cross-sectional area of the gluteus maximus was at the level of just above the femoral head $(23,24)$. The level just above the femoral head is closest to the maximum projection of the buttocks. The SIJ's lowest point is above the femoral head, and the ischial tuberosity is located under the femoral head. Therefore, measurement at the above 3 positions can better reflect the arc-shaped structure, and physiological and anatomical characteristics of the gluteus maximus muscle.

With the advent of solid silicone implants, the parameters of the implant dimensions took precedence over the volume in the selection of the correct implant (25). While the diameter of the prosthesis should depend on the width of the gluteus maximus muscle, if the diameter of the prosthesis is too large, i.e., beyond the muscle boundary, a postoperative unnatural protrusion will occur. By contrast, if the diameter of the prosthesis is too small, the postoperative 
cosmetics of the buttocks will be poor (25). According to our measurement results, we found that the level above the femoral head was closer to the maximum width of the gluteus maximus muscle. Therefore, the diameter of the prosthesis implanted into the gluteus maximus should not exceed the length of the $\mathrm{OC}$ on the level just above femoral head $(141.76 \pm 12.15 \mathrm{~mm})$. It should be noted that an MRI performed in the supine position compresses the gluteus maximus, which may lead to a discrepancy between the measured results and those found in actual clinical practice.

The thickness of the gluteus maximus is an important parameter for the procedure, which must be considered in order to define how thick the implant pocket should be $(25,26)$. According to our measurement results, the thickness of the gluteus maximus at point $\mathrm{A}$ is $16.03 \pm 4.17 \mathrm{~mm}$ at the inferior point of the SIJ, $23.41 \pm 4.40 \mathrm{~mm}$ at just above the femoral head, and $24.74 \pm 7.58 \mathrm{~mm}$ at the ischial tuberosity. In comparison, the thickness of the gluteus maximus at point $B$ for these levels was $24.66 \pm 4.84,30.64 \pm 4.57$, and $29.55 \pm 6.88 \mathrm{~mm}$, respectively. These results reflected the morphological characteristics that the upper part of the gluteus maximus muscle is thinner than the lower part. The thickness of the starting point A is vital for surgeons to create a consistent thickness of superficial and posterior walls of the implant by reserving the appropriate superficial glutes thickness during the stripping thereof. To avoid the unequal thickness of the gluteus maximus dissection, the reserved superficial thickness of the gluteus maximus should be half of that of the thickness of point A. When the vertical approach is employed from the surface of the gluteus maximus directly below $\mathrm{A}^{\prime}$, the reserved thickness of the superficial gluteus maximus should be $8.00 \pm 4.17 \mathrm{~mm}$ at the inferior point of the SIJ, $11.70 \pm 4.40 \mathrm{~mm}$ at the just above femoral head, and $12.3 \pm 7.58 \mathrm{~mm}$ at the ischial tuberous. If the separation of the gluteus maximus is too shallow (superficial thickness less than the range), muscle herniation may occur after surgery. On the contrary, if the separation exceeds this range for the superficial layer, it is easy to cause postoperative blood supply dysfunction for the deep gluteus maximus. It is worth noting that the thickness of the gluteus maximus at point $\mathrm{A}$ is not the thickest or thinnest of the gluteus maximus but the thickness of the surgery starting point.

We used the $\angle \mathrm{LOA}$ at different levels to explore the shape of the hip muscles. Our measurement results showed that $\angle \mathrm{LOA}$ was about $70^{\circ}$ at the inferior point of the SIJ level, about $62^{\circ}$ at the just above femoral head level, and about $90^{\circ}$ at the ischial tuberosity level, which indicated an arc-shaped structure of the muscles. Our results are in line with what was reported by Vergara $e t$ al., as the arc-shaped structure of the hip muscles caused a tilt in the approach route to the deep surface by $45^{\circ}$. This often occurred when separating the hip muscles to avoid passing through the superficial muscles and entering the subcutaneous layer $(11,12)$. However, the gluteal muscles tilted at $45^{\circ}$ to the deep surface mentioned in the literature are not close to the angle in the data that we measured. This may be related to the fact that the literature does not specify the position of the tilt.

During an operation, surgeons can access the approximate positions of $\mathrm{O}, \mathrm{A}, \mathrm{B}$, and $\mathrm{C}$ by their skin projection points of $\mathrm{O}^{\prime}, \mathrm{A}^{\prime}, \mathrm{B}^{\prime}$, and $\mathrm{C}^{\prime}$. Our results showed some differences between the left side and right side for those points at the 3 levels, which is consistent with the natural anatomical characteristics of humans (27). Nevertheless, it is almost impossible to locate them accurately during the operative separation of the gluteus maximus. The supplementary $\angle \mathrm{A}^{\prime} \mathrm{AB}$ and the supplementary $\angle \mathrm{ABC}$ were used to determine the position of $\mathrm{B}$ and $\mathrm{C}$. The supplementary $\angle \mathrm{A}^{\prime} \mathrm{AB}$ is the angle from which $\mathrm{AA}^{\prime}$ should turn to point $\mathrm{B}$, and the supplementary $\angle \mathrm{ABC}$ is the angle from which $A B$ should turn to point $C$. The surgeon approached from skin projection point $\mathrm{A}^{\prime}$ vertically into the glutes surface to point A during the operation. $\mathrm{He} /$ she then followed the supplementary $\angle \mathrm{A}^{\prime} \mathrm{AB}$ to strip the glutes laterally, until directly under the $\mathrm{B}^{\prime}$ point where point $\mathrm{B}$ is located. Next, a surgeon follows the supplementary $\angle A B C$ from point $\mathrm{B}$ to separate the muscle further laterally to point $\mathrm{C}$ (the endpoint of dissection), under projection $\mathrm{C}^{\prime}$. According to our measurement results, both the left and right supplementary $\angle \mathrm{A}^{\prime} \mathrm{AB}$ was about $63^{\circ}$ at the inferior point of the SIJ, $70^{\circ}$ at the just above femoral head, and $76^{\circ}$ at the ischial tuberosity. In comparison, the supplementary $\angle \mathrm{ABC}$ was about $-3^{\circ}\left(3^{\circ}\right.$ to the superficial gluteus maximus $), 1^{\circ}$, and $6^{\circ}$, accordingly. We believe that the ideal separation route can be found when separating the gluteus maximus muscle by referring to the above angle. However, through further analysis and consideration of the data, it can be found that all the supplementary $\angle \mathrm{ABC}$ in the 3 positions were not more than $6^{\circ}$, which may have no clinical significance. We assume that a vertical approach to the surface of the gluteus maximus directly below A' should follow after a single angle correction of the supplementary $\angle A^{\prime} A B$ at point $A$. This process continues to separate laterally until it reaches the lateral boundary of the gluteus maximus (point $\mathrm{C}$ ), which can equally divide the gluteus 
maximus into 2 parts. Therefore, it is not necessary to find point $\mathrm{B}$ or adjust the approach direction at any point intraoperatively.

The surgeon typically needs to mark the scope of the anatomy and the approximate location of the prosthesis before surgery. Horn et al. believe that the skin position will change from the standing position to the prone position, and that the preoperative marking should be made in the standing or sitting position (28). The medial, lateral, upper, and lower boundaries of the operation have been defined by different authors and were generally similar but exhibit inconsistencies in their defining methods $(9,20-22,28,29)$. According to the medial boundary mentioned in the literature, the 2 parallel boundary lines are $4-5 \mathrm{~cm}$ from the posterior midline. Our measurement results showed that the distance between $\mathrm{A}^{\prime}$ and the posterior midline was about $54 \mathrm{~mm}$ at the inferior point of the SIJ level, $55 \mathrm{~mm}$ at just above the femoral head level, and $73 \mathrm{~mm}$ at the ischial tuberosity level. All the locations of point A' were outside the medial boundary at all 3 levels, which indicated that point $\mathrm{A}$ is a suitable position for the anatomical approach.

Aboudib et al. reported no statistical correlation between the cosmetic effect evaluated by plastic surgeons and the volume of the prosthesis, or between the volume of the prosthesis and the volume of the muscle. Therefore, they believed that a preoperative computed tomography (CT) scan was not necessary for the operation (30). An MRI is more expensive than CT and is generally not a preoperative routine inspection for buttock augmentation. In the present study, all the predetermined MRI anatomic measurement indexes exhibited physiological significance and can truly reflect the morphological characteristics of the gluteus maximus muscle in a natural physiological state. The measurement results can provide real and objective data references for clinical practice and provide an anatomical basis and clinical reference for intramuscular prosthetic buttock augmentation.

In summary, at the level of inferior point of the SIJ, the starting point (A point) should be $54.4 \pm 6.34 \mathrm{~mm}$ away from the posterior midline. Then, a vertical approach of $8.0 \pm 4.17 \mathrm{~mm}$ should be made from the gluteus maximus surface. Finally, the line should be tilted $63.4 \pm 4.62^{\circ}$ to the deep plane to separate the gluteus maximus. At the level just above the femoral head, the gluteus maximus should be separated at the angle of $70 \pm 4.40^{\circ}$ to the deep plane after a $11.7 \pm 4.40 \mathrm{~mm}$ vertical approach from the surface of the gluteus maximus and a starting point of $54.91 \pm 5.57 \mathrm{~mm}$ away from the posterior midline. At the level of ischial tuberosity, the starting point (A point) should be $73.91 \pm 5.57 \mathrm{~mm}$ away from the posterior midline and the gluteus maximus should be divided evenly into 2 parts by a vertical approach of $12.3 \pm 7.58 \mathrm{~mm}$. After that, an angle of $70 \pm 4.40^{\circ}$ should be followed to further separate the muscle.

The innovations of this study are as follows. (I) It was the first study to observe the physiological anatomy of the gluteus maximus muscle through MRI and provide anatomical reference data for gluteus maximus implant augmentation. (II) Standardized measurement of the scheduled anatomical levels of the gluteus maximus muscle was carried out in the transverse section of pelvic MRI with 3 obvious bone markers. This was performed to reflect the physiological radian and thickness of the gluteus maximus muscle and avoid the limitation of a single position measurement. There were also some limitations of this study. First, as the pelvic MRI in this study was conducted in the supine position, it may exhibit a certain influence on the shape and thickness of soft tissues, leading to a discrepancy between the measured results and the true data. Next, although the sample size of 52 was enough to generate clinically significant results in practice, larger scale studies in the future are needed to confirm our findings. Third, the fact that all included patients were Chinese women may affect the external validity of this work to some degree. In addition, the physiological structure of the gluteus maximus muscle is correlated with the width and height of the pelvis; however, we did not have enough data to explore such an association. Therefore, we plan to further explore the relationship between the pelvis and the gluteus maximus muscle in the future. In addition, this study was a retrospective analysis, which is likely to exhibit some bias in the results. These results need to be further confirmed by multi-center clinical trials. The patients included in this study were all Chinese women who had certain limitations in being able to generalize to the greater population. A comparative analysis with patients from other countries is also recommended.

\section{Conclusions}

In this study, we measured the anatomical features of the gluteus maximus at the levels of the inferior point of the SIJ, just above the femoral head, and at the ischial tuberosity using MRI. According to our results, the diameter of the implant should not exceed $14.18 \pm 1.22 \mathrm{~cm}$. In addition, the gluteus maximus at the lowest point of the SIJ and above the femoral head has an arc structure, which needs to be 
tilted to the deep plane during separation. However, the gluteus maximus at the ischial tuberosity level is relatively flat, so the gluteus maximus at this level does not need to be tilted too much to the deep plane. Clinicians can use all the parameters indicated in this study, including the thickness of the gluteus maximus muscle in the above 3 levels, the position and angle of the "inflection point" after the surgical approach, and the approximate starting and ending point range of the gluteus maximus muscle. As an alternative to the previous experience of blind dissection, the gluteus maximus muscle can be more scientifically and reasonably dissected using the indexes for gluteus augmentation supplied in the study, which has certain clinical significance.

\section{Acknowledgments}

This work would not have been possible without the consistent and valuable reference materials that we received from Dr. Xiang Zhang (Affiliation: Sun Yat-sen Memorial Hospital, Sun Yat-sen University), whose insightful guidance and enthusiastic encouragement during the study has earned our deepest gratitude.

Funding: None.

\section{Footnote}

Reporting Checklist: The authors have completed the STROBE reporting checklist. Available at https://atm. amegroups.com/article/view/10.21037/atm-22-376/rc

Data Sharing Statement: Available at https://atm.amegroups. com/article/view/10.21037/atm-22-376/dss

Conflicts of Interest: All authors have completed the ICMJE uniform disclosure form (available at https://atm. amegroups.com/article/view/10.21037/atm-22-376/coif). The authors have no conflicts of interest to declare.

Ethical Statement: The authors are accountable for all aspects of the work in ensuring that questions related to the accuracy or integrity of any part of the work are appropriately investigated and resolved. All procedures performed in this study involving human participants were in accordance with the Declaration of Helsinki (as revised in 2013). The protocol of the study was approved by the Research Ethics Board of Sun Yat-sen Memorial Hospital, Sun Yat-sen University (No. SYSEC-KY-KS-2021-298). Informed consent was waived due to the retrospective and anonymous characteristics of the study.

Open Access Statement: This is an Open Access article distributed in accordance with the Creative Commons Attribution-NonCommercial-NoDerivs 4.0 International License (CC BY-NC-ND 4.0), which permits the noncommercial replication and distribution of the article with the strict proviso that no changes or edits are made and the original work is properly cited (including links to both the formal publication through the relevant DOI and the license). See: https://creativecommons.org/licenses/by-nc-nd/4.0/.

\section{References}

1. Heidekrueger PI, Juran S, Patel A, et al. Plastic Surgery Statistics in the US: Evidence and Implications. Aesthetic Plast Surg 2016;40:293-300.

2. Almutairi K, Gusenoff JA, Rubin JP. Body Contouring. Plast Reconstr Surg 2016;137:586e-602e.

3. Oranges CM, Haug M, Schaefer DJ. Body Contouring. Plast Reconstr Surg 2016;138:944e-5e.

4. Cosmetic Surgery National Data Bank Statistics. Aesthet Surg J 2016;36 Suppl 1:1-29.

5. Senderoff DM. Aesthetic Surgery of the Buttocks Using Implants: Practice-Based Recommendations. Aesthet Surg J 2016;36:559-76.

6. Mofid MM, Gonzalez R, de la Peña JA, et al. Buttock augmentation with silicone implants: a multicenter survey review of 2226 patients. Plast Reconstr Surg 2013;131:897-901.

7. Flores-Lima G, Eppley BL, Dimas JR, et al. Surgical pocket location for gluteal implants: a systematic review. Aesthetic Plast Surg 2013;37:240-5.

8. Oranges CM, Tremp M, di Summa PG, et al. Gluteal Augmentation Techniques: A Comprehensive Literature Review. Aesthet Surg J 2017;37:560-9.

9. Serra F, Aboudib JH, Cedrola JP, et al. Gluteoplasty: anatomic basis and technique. Aesthet Surg J 2010;30:579-92.

10. Xue B, Liu L. Research progress of hip aesthetics and extended plastic surgery. Chinese Journal of Aesthetic Medicine 2015;24:81-5.

11. Vergara R, Marcos M. Intramuscular gluteal implants. Aesthetic Plast Surg 1996;20:259-62.

12. Vergara R, Amezcua H. Intramuscular gluteal implants: 15 years' experience. Aesthet Surg J 2003;23:86-91.

13. Gonzalez R. Gluteal implants: the "XYZ" intramuscular method. Aesthet Surg J 2010;30:256-64. 
14. Gonzalez R, Gonzalez R. Intramuscular Gluteal Augmentation: The XYZ Method. Clin Plast Surg 2018;45:217-23.

15. González-Ulloa M. Gluteoplasty: a ten-year report. Aesthetic Plast Surg 1991;15:85-91.

16. González-Ulloa M. Torsoplasty. Aesthetic Plast Surg 1979;3:357-68.

17. Yahyavi-Firouz-Abadi N, Menias CO, Bhalla S, et al. Imaging of cosmetic plastic procedures and implants in the body and their potential complications. AJR Am J Roentgenol 2015;204:707-15.

18. Tothill P, Stewart AD. Estimation of thigh muscle and adipose tissue volume using magnetic resonance imaging and anthropometry. J Sports Sci 2002;20:563-76.

19. Nakatani M, Takai Y, Akagi R, et al. Validity of muscle thickness-based prediction equation for quadriceps femoris volume in middle-aged and older men and women. Eur J Appl Physiol 2016;116:2125-33.

20. Andrade GA, Coltro PS, Andó A, et al. Gluteal Augmentation with Silicone Implants: A New Proposal for Intramuscular Dissection. Aesthetic Plast Surg 2017;41:872-7.

21. Cárdenas-Camarena L, Trujillo-Méndez R, Díaz-Barriga JC. Tridimensional Combined Gluteoplasty: Liposuction, Buttock Implants, and Fat Transfer. Plast Reconstr Surg 2020;146:53-63.

22. Godoy PM, Munhoz AM. Intramuscular Gluteal Augmentation with Implants Associated with Immediate

Cite this article as: Zhang J, Wong CL, Zhang J, Su Z, Shi F, Chen C, Wang Y, Xiao X, Liang W, Zhang J. Clinical use of magnetic resonance imaging in buttock augmentation with silicone implants: a retrospective analysis. Ann Transl Med 2022;10(4):221. doi: 10.21037/atm-22-376
Fat Grafting. Clin Plast Surg 2018;45:203-15.

23. Homma D, Minato I, Imai N, et al. Investigation on the measurement sites of the cross-sectional areas of the gluteus maximus and gluteus medius. Surg Radiol Anat 2019;41:109-15.

24. Homma D, Minato I, Imai N, et al. Appropriate sites for the measurement of the cross-sectional area of the gluteus maximus and the gluteus medius muscles in patients with hip osteoarthritis. Surg Radiol Anat 2021;43:45-52.

25. Mendieta CG. Gluteoplasty. Aesthet Surg J 2003;23:44155 .

26. Cuenca-Guerra R, Lugo-Beltran I. Beautiful buttocks: characteristics and surgical techniques. Clin Plast Surg 2006;33:321-32.

27. Standring S, Ellis H, Healy J, et al. Gray's anatomy: the anatomical basis of clinical practice. Am J Neuroradiol $2005 ; 26: 2703$.

28. Horn G. Gluteoplasty with intramuscular silicone cohesive gel implants: a retrospective study of 50 cases. Ann Chir Plast Esthet 2009;54:467-76.

29. Aslani A, Del Vecchio DA. Composite Buttock Augmentation: The Next Frontier in Gluteal Aesthetic Surgery. Plast Reconstr Surg 2019;144:1312-21.

30. Aboudib JH, Serra-Guimarães F, Sampaio FJ. Profile of Patients Undergoing Gluteoplasty. Aesthetic Plast Surg 2016;40:30-7.

(English Language Editor: J. Jones) 